\title{
Vitamin A deficiency induces structural and functional alterations in the molecular constituents of the rat hippocampus
}

\author{
Birsen Elibol-Can ${ }^{1}$, Nihal Simsek-Ozek ${ }^{2}$, Feride Severcan $^{2 *}$, Mete Severcan $^{3}$ \\ and Ewa Jakubowska-Dogru ${ }^{2}$ \\ ${ }^{1}$ Department of Medical Biology, Faculty of Medicine, Bezmialem Vakif University, Istanbul 34093, Turkey \\ ${ }^{2}$ Department of Biological Sciences, Middle East Technical University, Ankara 06531, Turkey \\ ${ }^{3}$ Department of Electrical and Electronics Engineering, Middle East Technical University, Ankara 06531, Turkey
}

(Submitted 17 December 2013 - Final revision received 15 September 2014-Accepted 1 October 2014-First published online 17 November 2014)

\section{Abstract}

To date, no structural study has been carried out on the effects of vitamin A deficiency (VAD) on hippocampal macromolecules. Therefore, in the present study, the effect of dietary VAD on the structure, content and function of rat hippocampal molecules was investigated using Fourier transform IF spectroscopy. Male Wistar rats were randomly divided into three groups: an experimental group maintained on a vitamin A-deficient liquid diet (VAD, $n$ 7); a control group maintained on a vitamin A-supplemented liquid diet (CON, $n$ 9); a pure control group maintained on standard solid laboratory chow (PC, $n$ 7). The PC group was included in the study to ensure that the usage of liquid diet did not influence the outcomes of VAD. Both the CON and PC groups were successfully discriminated from the VAD group by principal component analysis and hierarchical cluster analysis. The spectral analysis indicated a significant decrease in the contents of saturated and unsaturated lipids, cholesteryl esters, TAG and nucleic acids in the VAD group when compared with the CON group $(P \leq 0.05)$. In addition, a significant decrease in membrane fluidity and a significant increase in lipid order (e.g. acyl chain flexibility) were observed in the VAD group $(P \leq 0 \cdot 001)$. The results of the artificial neural network analysis revealed a significant decrease in the $\alpha$-helix structure content and a significant increase in the turn and random coil structure contents, indicating protein denaturation, in the VAD group when compared with the CON and PC groups $(P \leq 0.05)$. Dietary exclusion of vitamin A for 3 months apparently had an adverse impact on compositional, structural and dynamical parameters. These changes can be due to increased oxidative stress, confirming the antioxidant protection provided by vitamin A when used as a dietary supplement at low-to-moderate doses.

Key words: Vitamin A: Hippocampus: Protein secondary structure: Fourier transform IR spectroscopy: Lipids: Nucleic acids

Vitamin A (retinol) is one of the most commonly used dietary supplements. Retinoic acid, a derivative of vitamin A, has been demonstrated to play an important signalling role during prenatal development ${ }^{(1)}$. Vitamin A is also indispensable throughout the postnatal phase due to its effects on cell metabolism, retinal photo-pigment production, epithelial cell differentiation, bone growth, immune processes and reproduction $^{(2,3)}$. A relatively low dose of vitamin A (about $8500 \mathrm{IU} / \mathrm{kg}$ per $\mathrm{d}$ ) is administered to infants with a very low birth weight ${ }^{(4)}$, while high doses (about 50000-100 $000 \mathrm{IU} / \mathrm{d}$ ) are used for therapeutic purposes in patients with leukaemia $^{(5)}$. However, the dietary supplementation of vitamin A to healthy adult individuals is still a controversial issue. After documentation of its pro-oxidant properties when used at relatively high doses ${ }^{(6)}$, it has been suggested that vitamin A may act as a double-edged sword. The proand antioxidative actions of dietary supplements are especially important for the brain, which is known to be more susceptible to oxidative damage because of its high levels of oxygen consumption, rich content of easily oxidisable PUFA in cell membranes, relatively low contents of antioxidant enzymes such as catalase and superoxide dismutase as well as antioxidants such as $\alpha$-tocopherol and glutathione, and eventually the presence of high concentrations of $\mathrm{Fe}$ when compared with other organs ${ }^{(7,8)}$. In addition, certain regions of the central nervous system, such as the hippocampus and cerebellum, may be highly sensitive to oxidative stress because of their relatively low endogenous concentrations of vitamin $\mathrm{E}^{(9)}$. The protective role of antioxidants and the potential role of vitamin $\mathrm{A}$ in the

Abbreviations: ANN, artificial neural network; CON group, control rats maintained on a vitamin-supplemented liquid diet; FT-IR, Fourier transform IR; HCA, hierarchical cluster analysis; PC group, pure control rats maintained on standard solid laboratory chow; PCA, principal component analysis; VAD, vitamin A deficiency; VAD group, experimental rats maintained on a vitamin A-deficient liquid diet. 
modulation of oxidative stress in the central nervous system have been reported previously ${ }^{(10)}$.

Animal studies have also demonstrated the importance of vitamin $\mathrm{A}$ in the neurogenesis ${ }^{(11)}$ and metaplasticity ${ }^{(12)}$ of the hippocampus, which is the brain structure crucial for learning and memory formation. A reduction in hippocampal Cornu Ammonis 1 (CA1) long-term potentiation and long-term depression have been observed in adult mice maintained on a vitamin A-deficient diet. Subsequent administration of vitamin $\mathrm{A} /$ retinoic acid has been reported to reverse deficits in hippocampal plasticity ${ }^{(12)}$. Parallel to these findings, hippocampus-dependent spatial learning has also been shown to deteriorate in vitamin A-deficient rats ${ }^{(11,13,14)}$. Considering the importance of vitamin A in many physiological processes, the high prevalence of vitamin A deficiency (VAD) occurring along with malnutrition in many African and Asian countries has been suggested to cause serious health problems ${ }^{(15)}$. Therefore, further studies on the biological role of vitamin A and the impact of VAD on biological systems are important from a clinical perspective. The effects of vitamin A supplementation and VAD at the organismal and cellular levels have been largely disclosed. However, VAD-related structural and functional changes occurring at the molecular level have not been elucidated yet. Therefore, the aim of the present study was to examine the effect of VAD on the structure, content and function of lipids, proteins and nucleic acids in the rat hippocampus, which, to the best of our knowledge, has not been investigated yet, and thus to contribute to the elucidation of the cellular mechanisms underlying VAD in the hippocampus. To achieve this, Fourier transform IR (FT-IR) spectroscopy was used as many studies have proved that it is a powerful and successful analytical technique that provides qualitative and/or quantitative information. This technique allows rapid, accurate, reproducible, cost-effective and operator-independent determination of global molecular alterations at the membrane, cellular and tissue levels ${ }^{(16-23)}$. FT-IR spectroscopy exhibits higher sensitivity in detecting even very small changes in the functional groups of biological molecules without the use of stains or probes. Using this method, comprehensive information about membrane fluidity, lipid order, the contents of saturated lipids, unsaturated lipids, cholesteryl ester, TAG, proteins, RNA, DNA and glycogen, and protein and nucleic acid conformation can be obtained rapidly and simultaneously from a single tissue sample ${ }^{(7,21-23)}$.

\section{Materials and methods}

\section{Experimental animals}

Naive, male Wistar rats ( $n$ 23) aged 3 months and weighing 200-250 g were obtained from Animal Facilities at Gulhane Medical Military Academy, Ankara, Turkey. Rats were housed in a secluded room at an ambient temperature of $22^{\circ} \mathrm{C}$, under a $12 \mathrm{~h}$ light $-12 \mathrm{~h}$ dark cycle, and with free access to standard laboratory chow and tap water until the start of the experiment. The institutional and national guidelines for the care and use of animals were followed in the present study and all experimental procedures involving animals were approved by the Ethics Committee of the Middle East Technical University, Ankara, Turkey.

\section{Treatment}

Rats were randomly divided into three groups: an experimental group maintained on a vitamin A-deficient liquid diet (VAD, $n$ 7); a control group maintained on a vitamin Asupplemented liquid diet (CON, $n$ 9); a pure control group maintained on standard solid laboratory chow (PC, $n$ 7). The PC group was included in the study to ensure that the usage of liquid diet did not influence the outcomes of VAD. Rats form the VAD group were fed a $100 \mathrm{ml}$ mixture of a modified liquid diet prepared with semi-skimmed milk (Pinar Co.) and sucrose (Merck) for $85 \mathrm{~d}$ daily as described previously ${ }^{(24)}$. Rats from the CON group were fed a liquid diet supplemented with 5000 IU/1 vitamin A (Avicap; Kocak Farma). The mean total daily energy intake of each rat was $209 \mathrm{~kJ}$ ( $50 \mathrm{kcal})$. On the 86th day, rats were decapitated and their hippocampi were dissected and stored at $-80^{\circ} \mathrm{C}$ until the FT-IR analysis.

\section{Sampling, data acquisition and Fourier transform IR spectroscopy}

Hippocampal samples were dried in a Labconco freeze dryer (6 Liter Benchtop Freeze Dry System Model 77520; Labconco FreeZone ${ }^{\circledR}$ ) to remove free water content. Later, $1 \mathrm{mg}$ of the samples was ground in agate mortar containing liquid $\mathrm{N}_{2}$ and mixed with $150 \mathrm{mg}$ of $\mathrm{KBr}$ (Merck). This homogeneous mixture was used to prepare thin $\mathrm{KBr}$ discs by applying pressure of approximately $100 \mathrm{~kg} / \mathrm{cm}^{2}$ in an evacuated die. IR spectra were obtained using a PerkinElmer Spectrum One FT-IR spectrometer (PerkinElmer, Inc.) equipped with a mid IR triglycine sulphate (MIR TGS) detector. The background spectrum was recorded using a transparent $\mathrm{KBr}$ disc without the sample and subtracted automatically using the Spectrum One software (PerkinElmer, Inc.). The FT-IR spectrum was recorded in the $4000-800 / \mathrm{cm}$ region by collecting 100 scans per sample with $4 / \mathrm{cm}$ resolution at room temperature. The average spectra of three replicates from each sample were used in detailed data analysis. The nine-point SavitzkyGolay smoothing function was applied to reduce noise ${ }^{(25)}$. The band frequency, band area and bandwidth values of each spectrum were calculated from the spectral bands using the Spectrum One software. Baseline correction was performed as an input parameter in the band area calculations. The frequency and width values of specific bands were calculated as the centre of mass and width, respectively, at $0.80 \times$ height position of the signal in terms of per $\mathrm{cm}$ where overlapping with the other bands was minimum. Normalisation processes were applied for visual demonstration of only spectral variations.

The general band assignment of the FT-IR spectra was done in accordance with previous studies ${ }^{(7,25-27)}$ and is summarised in Table 1. The area under the peaks gives information about the concentration of the related functional groups, and the changes in frequency correspond to the structural variations in macromolecules, while the width of the $\mathrm{CH}_{2}$ stretching 
Table 1. General band assignment of the hippocampal tissue

\begin{tabular}{|c|c|c|}
\hline Peak no. & Wavenumber $\left(\mathrm{cm}^{-1}\right)$ & Definition of the spectral assignment \\
\hline 1 & 3350 & $\begin{array}{l}\text { Amide A (mainly } \mathrm{N}-\mathrm{H} \text { stretching of the hydrogen-bonded amide groups of proteins with some } \\
\text { contribution from the } \mathrm{O}-\mathrm{H} \text { stretching of polysaccharides and intermolecular hydrogen } \\
\text { bonding of proteins and glycogen) }\end{array}$ \\
\hline 2 & 3014 & Olefinic $\mathrm{H}-\mathrm{C}-\mathrm{C}-\mathrm{H}$ stretching vibration: unsaturated lipids \\
\hline 3 & 2960 & $\begin{array}{l}\mathrm{CH}_{3} \text { asymmetric stretching: mainly lipids, with some contribution from proteins, carbohydrates } \\
\text { and nucleic acids }\end{array}$ \\
\hline 4 & 2924 & $\begin{array}{l}\mathrm{CH}_{2} \text { asymmetric stretching: mainly lipids, with some contribution from proteins, carbohydrates } \\
\text { and nucleic acids }\end{array}$ \\
\hline 5 & 2872 & $\begin{array}{l}\mathrm{CH}_{3} \text { symmetric stretching: mainly proteins, with some contribution from lipids, carbohydrates } \\
\text { and nucleic acids }\end{array}$ \\
\hline 6 & 2852 & $\begin{array}{l}\mathrm{CH}_{2} \text { symmetric stretching: mainly lipids, with some contribution from proteins, carbohydrates } \\
\text { and nucleic acids }\end{array}$ \\
\hline 7 & 1745 & Carbonyl $\mathrm{C}-\mathrm{O}$ stretching in phospholipids, cholesteryl esters and TAG \\
\hline 8 & 1655 & Amide I (C-O stretching in proteins $(80 \%))$ \\
\hline 9 & 1544 & Amide II (proteins, $\mathrm{N}-\mathrm{H}$ bending $(60 \%)$ and $\mathrm{C}-\mathrm{N}$ stretching $(40 \%))$ \\
\hline 10 & 1460 & $\mathrm{CH}_{2}$ bending: mainly lipids, with some contribution from proteins \\
\hline 11 & 1394 & $\mathrm{COO}^{-}$symmetric stretching: fatty acids and amino-acid side groups \\
\hline 12 & 1305 & Amide III (protein C-N stretching (40\%), N-H bending (30\%) and C-C stretching $(20 \%)$ ) \\
\hline 13 & 1237 & $\mathrm{PO}_{2}^{-}$asymmetric stretching: mainly nucleic acids with some contribution from phospholipids \\
\hline 14 & 1170 & $\mathrm{CO}-\mathrm{O}-\mathrm{C}$ asymmetric stretching: phospholipids and cholesteryl esters \\
\hline 15 & 1065 & $\mathrm{C}-\mathrm{O}$ stretching of the phosphodiester and ribose: nucleic acids, in the absence of glycogen \\
\hline 16 & 995 & $\mathrm{C}-\mathrm{N}^{+}-\mathrm{C}$ stretching: nucleic acids, ribose-phosphate main chain vibrations of RNA \\
\hline 17 & 926 & Left-handed helix DNA ( $Z$ form) \\
\hline 18 & 875 & $\mathrm{~N}$-type sugars in the nucleic acid backbone (A-form helix) \\
\hline
\end{tabular}

bands provides information about lipid dynamics ${ }^{(25,28)}$. Band area ratios were calculated by comparing the areas of specific spectral bands.

\section{Prediction of the secondary structure of proteins}

The secondary structure of proteins was predicted using the artificial neural network (ANN) method based on the amide I band located between the 1700 and $1600 / \mathrm{cm}$ regions ${ }^{(17,19,26)}$. The amide I band was pre-processed by normalisation and discrete cosine transformation. The neural networks were first trained using a dataset containing the FT-IR spectra of eighteen water-soluble proteins recorded in water by Bayesian regularisation $^{(29,30)}$. For each structure parameter, a separate ANN with the number of inputs, i.e. the number of discrete cosine transformation coefficients, and the number of hidden neurons optimised was trained. The secondary structure parameters of proteins were predicted by applying the pre-processed FT-IR data to the inputs of the trained ANN.

The secondary structure of proteins was determined by performing intensity reading of the second-derivative spectra using the amide I band $\left(1700-1600 \mathrm{~cm}^{-1}\right)$ with the OPUS ${ }^{\mathrm{NT}}$ data collection software package (Bruker Optics $\mathrm{GmbH}$ ) as described in detail previously ${ }^{(17)}$.

\section{Hierarchical cluster analysis and principal component analysis}

Hierarchical cluster analysis (HCA) and principal component analysis (PCA) were carried out to characterise the study groups based on spectral variations. HCA was performed using the cluster analysis module of the OPUS 5.5 software. The second-derivative and vector-normalised spectra of samples (in the $1700-1600 \mathrm{~cm}^{-1}$ spectral region) were used in this analysis. Ward's algorithm was applied to construct dendrograms, using Pearson's product-correlation coefficient as a distance measure.

Specific software developed by the laboratory of Erik Goormaghtigh under MATLAB (MathWorks, Inc.) was used to carry out PCA. PCA was conducted using the average absorbance spectra utilising the first-derivative spectra in the $1700-1600 / \mathrm{cm}$ spectral region.

\section{Statistical analyses}

The results are presented as means with their standard errors. Spectral data were analysed using Student's $t$ test with the SPSS Statistical Software version 15.0 program (SPSS, Inc.). A $P$ value $\leq 0.05$ was considered to be statistically significant.

\section{Results}

The FT-IR spectra of hippocampal tissue in the 3800-3030/ $\mathrm{cm}, \quad 3030-2800 / \mathrm{cm}(\mathrm{C}-\mathrm{H})$ and $1800-400 / \mathrm{cm}$ (fingerprint) regions are shown in Fig. 1(a)-(c) for all the three groups. The main bands are labelled in the figures and the general band assignment is summarised in Table 1. Spectral calculation of the band area and frequency (Table 2) and bandwidth and band area ratio (Table 3) was performed to determine the VAD-induced alterations in the content, structure and function of molecules. Lastly, the secondary structure of proteins was determined (Table 4). Based on spectral variations, the VAD, CON and PC groups were successfully differentiated by HCA and PCA (Fig. 2(a) and (b)).

As can be seen from Fig. 1(a)-(c) and Tables 2 and 3, there were no significant differences in the areas and area ratios of all the studied bands in the CON and PC groups. Therefore, the VAD group was compared with the CON group with 

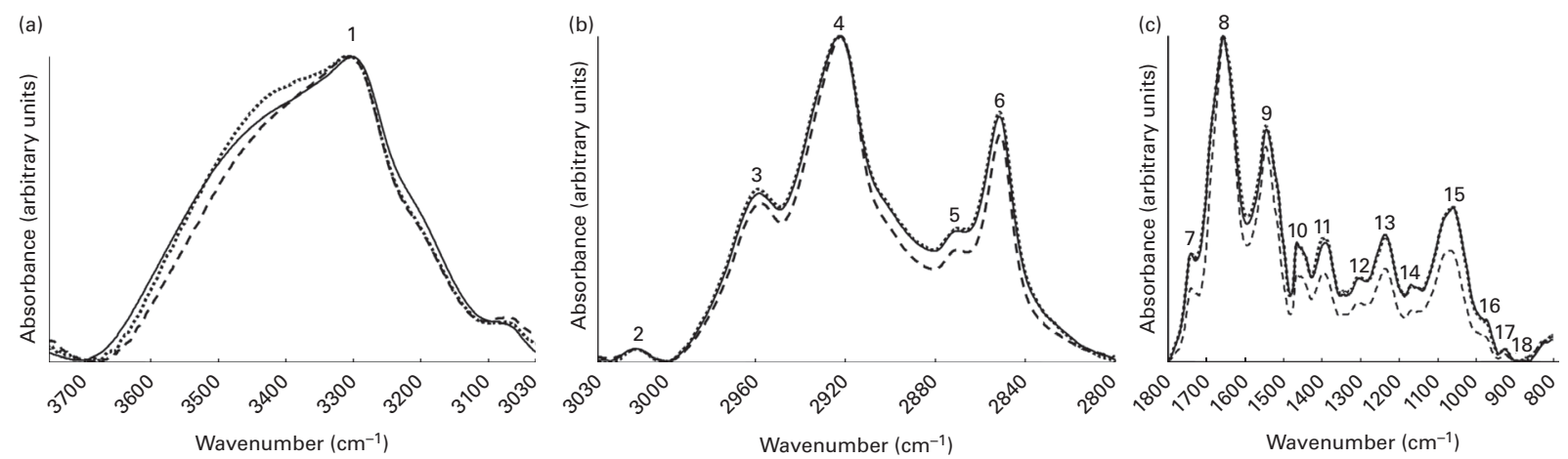

Fig. 1. IR spectra of hippocampal tissue in the (a) 3800-3030/cm region normalised with respect to the amide A mode at $3306 / \mathrm{cm}$, (b) $3030-2800 / \mathrm{cm}$ region normalised with respect to the $\mathrm{CH}_{2}$ asymmetric stretching mode at $2924 / \mathrm{cm}$, and (c) $1800-400 / \mathrm{cm}$ region normalised with respect to the amide I mode at $1654 / \mathrm{cm}$ in the pure control (-), control (.......) and vitamin A-deficient (---) groups. Description of numerals above the bands is given in Table 1.

regard to hippocampal molecule content. The areas of spectral bands in the $\mathrm{CH}$ region were used to determine alterations in the lipid content among the study groups. The olefinic band located in the $3014 / \mathrm{cm}$ region was analysed to obtain information about unsaturated lipids, while the bands located in the 2924, 2872 and $2852 / \mathrm{cm}$ regions were used to obtain information about saturated lipids ${ }^{(31-33)}$. These data indicated a significant decrease in the contents of both saturated and unsaturated lipids in the VAD group when compared with the CON group ( $P \leq 0.05$; Fig. 1(b) and Table 2). This decrease in lipid content was also supported by the decrease in the area of another lipid band located in the $1459 / \mathrm{cm}$ region $(P \leq 0 \cdot 05$; Fig. 1(c) and Table 2). The decrease in the area of the olefinic band (Fig. 1(b) and Table 2) and thus the decrease in unsaturation of the system were additionally supported by the decrease in the olefinic- $\mathrm{CH}$ :lipid ratio (Table 3 ) in the VAD group. In addition, the ratios of some specific lipid functional groups to the sum of the $\mathrm{CH}_{2}$ asymmetric and symmetric stretching bands and $\mathrm{CH}_{3}$ asymmetric stretching band were investigated to determine the changes in lipid composition. A significant increase $(P \leq 0.001)$ was observed in the band area ratio of $\mathrm{CH}_{2}$ asymmetric stretching to total lipids in the VAD group when compared with the CON group. In contrast, a significant decrease was observed in the band area ratio of $\mathrm{CH}_{3}$ asymmetric stretching and carbonyl esters to total lipids ( $P \leq 0.001$ and $P \leq 0.01$, respectively) in the VAD group (Table 3). In addition to changes in these ratios, the lipid: protein ratio and the lipid ester:protein ratio were significantly reduced and the saturated:unsaturated lipid ratio was significantly elevated in the VAD group when compared with the CON group ( $P \leq 0 \cdot 001$; Table 3 ).

Reductions were also observed in the cholesteryl ester $\left(1744 \mathrm{~cm}^{-1}\right)$ and TAG $\left(1170 \mathrm{~cm}^{-1}\right)$ contents in the hippocampus of the VAD group when compared with the CON

Table 2. Detailed numerical summary of the differences in the frequency and area values of spectral bands in each group (Mean values with their standard errors)

\begin{tabular}{|c|c|c|c|c|c|c|c|c|c|c|c|c|}
\hline \multirow[b]{3}{*}{ Bands } & \multicolumn{6}{|c|}{ Band frequency } & \multicolumn{6}{|c|}{ Band area } \\
\hline & \multicolumn{2}{|c|}{ PC group ( $n 7)$} & \multicolumn{2}{|c|}{ CON group $(n 9)$} & \multicolumn{2}{|c|}{ VAD group $(n 7)$} & \multicolumn{2}{|c|}{ PC group $(n 7)$} & \multicolumn{2}{|c|}{ CON group $(n 9)$} & \multicolumn{2}{|c|}{ VAD group $(n 7)$} \\
\hline & Mean & SEM & Mean & SEM & Mean & SEM & Mean & SEM & Mean & SEM & Mean & SEM \\
\hline 1 & 3354.37 & 3.76 & 3348.58 & 3.30 & $3338.83 \downarrow$ * & 1.79 & 68.50 & $6 \cdot 37$ & $72 \cdot 17$ & $3 \cdot 76$ & $68.62 \downarrow$ & 2.53 \\
\hline 2 & $3014 \cdot 30$ & $0 \cdot 13$ & 3014.33 & 0.16 & $3013.85 \downarrow^{*}$ & 0.06 & 2.68 & 0.23 & $2 \cdot 74$ & 0.13 & $2 \cdot 10 \downarrow^{* *}$ & 0.06 \\
\hline 3 & $2960 \cdot 82$ & 0.09 & $2960 \cdot 77$ & 0.05 & $2959.67 \downarrow^{* \star *}$ & 0.05 & 6.58 & 0.56 & 6.83 & 0.35 & $5.41 \downarrow^{* *}$ & 0.17 \\
\hline 4 & $2924 \cdot 21$ & 0.08 & 2924.42 & 0.07 & $2923.42 \downarrow^{\star \star \star \star}$ & 0.03 & 11.25 & 0.96 & $11 \cdot 71$ & 0.63 & $9.81 \downarrow^{*}$ & 0.37 \\
\hline 5 & 2871.94 & 0.05 & 2871.83 & 0.02 & $2871.65 \downarrow$ ฝ* & 0.003 & 1.54 & 0.13 & 1.57 & 0.08 & $1.20 \downarrow$ ** & 0.04 \\
\hline 6 & $2852 \cdot 12^{\star}$ & 0.04 & $2852 \cdot 25$ & 0.03 & $2851.63 \downarrow^{\star \star \star \star}$ & 0.08 & 3.41 & 0.29 & 3.54 & 0.18 & $2 \cdot 82 \downarrow^{\star *}$ & 0.10 \\
\hline 7 & 1745.58 & 0.33 & 1744.89 & 0.30 & $1744.08 \downarrow^{*}$ & 0.09 & 3.39 & 0.32 & 3.45 & $0 \cdot 19$ & $2.58 \downarrow^{* *}$ & 0.04 \\
\hline 8 & 1655.06 & 0.18 & 1655.04 & 0.17 & $1654.06 \downarrow$ \*** & 0.06 & $20 \cdot 72$ & 1.94 & $23 \cdot 01$ & 1.41 & $21.90 \downarrow$ & 0.78 \\
\hline 9 & 1543.99 & $0 \cdot 13$ & 1544.01 & 0.07 & $1545 \cdot 27 \uparrow^{* \star *}$ & $0 \cdot 10$ & 13.92 & $1 \cdot 27$ & $15 \cdot 20$ & 0.89 & $13 \cdot 86 \downarrow$ & 0.45 \\
\hline 10 & $1459 \cdot 94$ & 0.23 & $1459 \cdot 42$ & 0.26 & $1459.69 \uparrow$ & 0.11 & 4.45 & 0.39 & 4.63 & 0.26 & $3.83 \downarrow^{*}$ & 0.13 \\
\hline 11 & 1394.48 & 0.48 & 1394.38 & 0.28 & $1395 \cdot 82 \uparrow^{\star \star}$ & 0.14 & $5 \cdot 69$ & 0.48 & 5.95 & 0.32 & $4.81 \downarrow$ ** & 0.15 \\
\hline 12 & $1305 \cdot 36$ & 0.64 & $1305 \cdot 04$ & 0.43 & $1303.92 \downarrow^{*}$ & 0.09 & $2 \cdot 91$ & 0.26 & 3.03 & $0 \cdot 18$ & $2.45 \downarrow^{*}$ & 0.07 \\
\hline 13 & 1237.48 & 0.11 & 1237.68 & 0.21 & $1236 \cdot 81 \downarrow^{* *}$ & 0.08 & $6 \cdot 77$ & 0.64 & $7 \cdot 17$ & 0.42 & $5.90 \downarrow^{*}$ & 0.17 \\
\hline 14 & $1170 \cdot 91^{*}$ & 0.46 & $1172 \cdot 43$ & 0.31 & $1170 \cdot 32 \downarrow^{* *}$ & 0.07 & 1.97 & $0 \cdot 19$ & 2.04 & $0 \cdot 11$ & $1.60 \downarrow^{* *}$ & 0.05 \\
\hline 15 & $1065 \cdot 18$ & 0.61 & 1066.58 & 0.64 & $1070 \cdot 01 \uparrow^{* *}$ & 0.52 & 11.54 & $1 \cdot 13$ & 11.87 & 0.74 & $9.44 \downarrow$ * & 0.35 \\
\hline 16 & $992 \cdot 21^{\star \star \star}$ & 0.58 & $995 \cdot 10$ & 0.23 & $989 \cdot 77 \downarrow^{\star \star *}$ & 0.08 & 1.62 & 0.19 & 1.48 & 0.12 & $1.04 \downarrow^{*}$ & 0.06 \\
\hline 17 & $926 \cdot 68$ & 0.36 & 926.06 & 0.20 & $927 \cdot 04 \uparrow^{\star \star}$ & 0.07 & 0.34 & 0.05 & 0.29 & 0.03 & $0.19 \downarrow$ * & 0.02 \\
\hline 18 & 874.91 & 0.43 & $874 \cdot 28$ & 0.24 & $873.08 \downarrow^{\star *}$ & 0.06 & 0.012 & 0.006 & 0.015 & 0.004 & $0.066 \uparrow^{\star * \star *}$ & 0.004 \\
\hline
\end{tabular}

PC group, pure control rats maintained on standard solid laboratory chow; CON group, control rats maintained on a vitamin A-supplemented liquid diet; VAD group, experimental rats maintained on a vitamin A-deficient liquid diet; $\downarrow$, decrease in the band frequency and band area in the VAD group with respect to the CON group; $\uparrow$, increase in the band frequency and band area in the VAD group with respect to the CON group.

Mean value was significantly different from that of the CON group: ${ }^{\star} P<0.05,{ }^{\star \star} P<0.01,{ }^{\star \star \star} P<0.001$. 
Table 3. Detailed numerical summary of the differences in the ratio of spectral bands in each group (Mean values with their standard errors)

\begin{tabular}{|c|c|c|c|c|c|c|}
\hline & \multicolumn{6}{|c|}{ Band ratio } \\
\hline & \multicolumn{2}{|c|}{ PC group ( $n 7)$} & \multicolumn{2}{|c|}{ CON group $(n 9)$} & \multicolumn{2}{|c|}{ VAD group $(n 7)$} \\
\hline & Mean & SEM & Mean & SEM & Mean & SEM \\
\hline Lipid:protein ratio & 1.030 & 0.010 & 0.984 & 0.021 & $0.824 \downarrow^{* * *}$ & 0.005 \\
\hline $\mathrm{CH}_{2}$ asymmetric:lipid ratio & 0.529 & 0.001 & 0.530 & 0.001 & $0.544 \uparrow^{* * *}$ & 0.001 \\
\hline $\mathrm{CH}_{3}$ asymmetric:lipid ratio & 0.310 & 0.001 & 0.310 & 0.001 & $0.300 \downarrow^{* \star *}$ & 0.001 \\
\hline Carbonyl ester:lipid ratio & 0.159 & 0.002 & 0.156 & 0.002 & $0.144 \downarrow^{* *}$ & 0.003 \\
\hline Amide I:amide II ratio & 1.487 & 0.006 & 1.508 & 0.009 & $1.579 \uparrow^{\star \star \star}$ & 0.006 \\
\hline Olefinic:lipid ratio & 0.126 & 0.001 & 0.124 & 0.001 & $0.117 \downarrow^{* *}$ & 0.001 \\
\hline
\end{tabular}

group ( $P \leq 0 \cdot 01$; Table 2 and Fig. 1(c)). In addition, a significant shift to lower levels was observed in the frequency of the ester band in the VAD group, while no differences were observed in the frequency when the control groups were compared with each other ( $P \leq 0 \cdot 05$; Table 2$)$.

The bandwidth and band frequency analyses of the $\mathrm{CH}_{2}$ asymmetric and symmetric stretching bands give information about lipid fluidity and lipid order, respectively ${ }^{(28,34)}$. In the present study, a significant decrease from 12.41 (SEM 0.05) to 5.90 (SEM 0.02 ) arbitrary units in the CON group, from 12.47 (SEM 0.05 ) to 5.89 (SEM 0.03) arbitrary units in the PC group, and from 12.08 (SEM 0.03 ) to 5.74 (SEM 0.02) arbitrary units in the VAD group was observed in the bandwidths of the $\mathrm{CH}_{2}$ asymmetric and symmetric stretching bands, which monitor lipid fluidity $(P \leq 0 \cdot 001)$. In addition, a significant shift to lower levels was observed in the frequencies of both bands in the VAD group $(P \leq 0.001)$ when compared with the CON group (Table 2). Conversely, a significant shift to higher levels was observed in the frequency of the $\mathrm{CH}_{2}$ symmetric stretching band in the CON group when compared with the PC group ( $P \leq 0.05$; Table 2$)$.

Alterations in the areas and frequencies of the amide I and II bands and the amide I:amide II ratio are commonly analysed to understand the changes in protein content and structure ${ }^{(16,33)}$. In the present study, a significant decrease in the frequency of the amide I band $(P \leq 0 \cdot 001)$ and a significant increase in the frequency of the amide II band $(P \leq 0 \cdot 001)$ were observed in the VAD group when compared with the CON group. However, no differences were observed in these frequencies when the control groups were compared with each other (Table 2). Moreover, the amide I:amide II ratio was significantly higher in the VAD group $(P<0.001$; Table 3). Significant shifts to lower levels $(P \leq 0 \cdot 05)$ were observed in the frequencies of the amide $\mathrm{A}$ and $\mathrm{CH}_{3}$ symmetric stretching and amide III bands, which also mainly originate from the functional groups of proteins, in the VAD group when compared with the CON group (Table 2).

To obtain more detailed information, the secondary structure of proteins was determined from the amide I band in the FT-IR spectra for all groups, using the ANN method and the measurement of the intensity of the second-derivative spectra. The ANN results (Table 4) revealed a significant decrease in the $\alpha$-helix structure content $(P \leq 0 \cdot 01)$ and a significant increase in the $\beta$-sheet $(P \leq 0.001)$, turn $(P \leq 0.001)$ and random coil $(P \leq 0.05)$ structure contents in the VAD group when compared with the CON group. As the increase in the random coil structure content indicates protein denaturation, this band was further investigated using a second approach, namely the measurement of the intensity of the second-derivative spectra. Using this approach, supporting neural network results, a significant increase in the random

Table 4. Changes in the secondary structure of proteins predicted using the artificial neural network method

(Mean values with their standard errors)

\begin{tabular}{|c|c|c|c|c|c|c|}
\hline \multirow[b]{2}{*}{ Functional groups } & \multicolumn{2}{|c|}{$\mathrm{PC}$ group $(n 7)$} & \multicolumn{2}{|c|}{ CON group ( $n 9)$} & \multicolumn{2}{|c|}{ VAD group $(n 7)$} \\
\hline & Mean & SEM & Mean & SEM & Mean & SEM \\
\hline$\alpha$-Helix & 77.04 & 1.82 & 73.70 & 1.33 & $64.92 \downarrow$ ** & 2.4 \\
\hline$\beta$-Sheet & $11 \cdot 91^{\star \star}$ & 0.34 & 13.86 & 0.44 & $16 \cdot 35 \uparrow^{\star \star \star *}$ & 0.2 \\
\hline Turns & 5.46 & 0.25 & $6 \cdot 37$ & 0.34 & $11 \cdot 10 \uparrow^{\star \star *}$ & 0.45 \\
\hline Random coils & 5.58 & 1.57 & 5.69 & 1.25 & $11.01 \uparrow *$ & $2 \cdot 30$ \\
\hline
\end{tabular}

PC group, pure control rats maintained on standard solid laboratory chow; CON group, control rats maintained on a vitamin A-supplemented liquid diet; VAD group, experimental rats maintained on a vitamin A-deficient liquid diet; $\downarrow$, decrease in the band frequency and band area in the VAD group with respect to the CON group; $\uparrow$, increase in the band frequency and band area in the VAD group with respect to the CON group. Mean value was significantly different from that of the CON group: ${ }^{\star} P<0.05,{ }^{* \star} P<0.01,{ }^{* \star *} P<0.001$. 
(a)

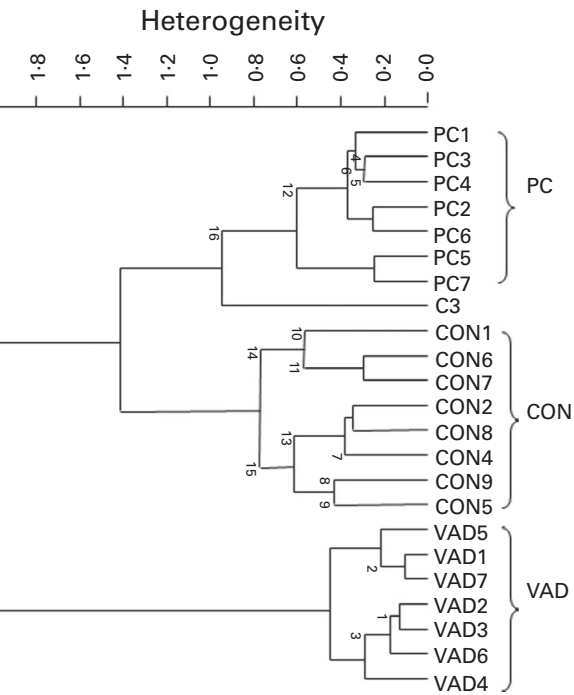

(b)

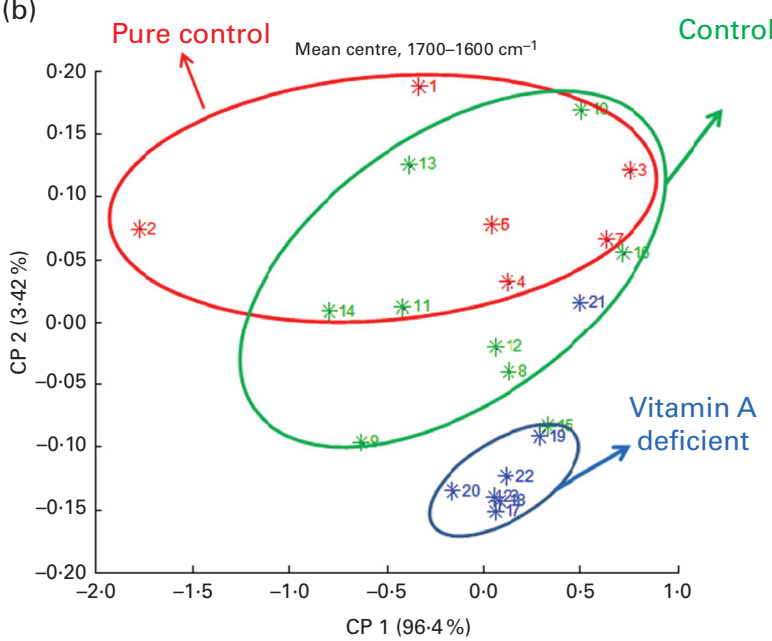

Fig. 2. Results of the (a) hierarchical cluster analysis and (b) principal component (CP) analysis of the Fourier transform IR spectra in the fingerprint region of the spectral range in the pure control $(\mathrm{PC})$, control $(\mathrm{CON})$ and vitamin A-deficient (VAD) groups. A colour version of this figure can be found online at http://www.journals.cambridge.org/bjn

coil structure content was detected in the VAD group when compared with the CON group (VAD: -0.113 (SEM 0.01), CON: -0.079 (SEM 0.02), and PC: -0.096 (SEM 0.01); $P<0.05)$, which also confirms protein denaturation. Conversely, a significant increase was observed in the $\beta$-sheet structure content in the CON group $(P \leq 0 \cdot 01)$ when compared with the PC group.

It has previously been shown that absorption in the $1300-900 / \mathrm{cm}$ range occurs due to several macromolecules including polysaccharides and phosphorylated compounds such as phospholipids and nucleic acids ${ }^{(25)}$. In the VAD group, when compared with the CON group, a significant increase in the frequency of the $\mathrm{COO}^{-}$symmetric stretching band $\left(1394 \mathrm{~cm}^{-1}\right)$ due to fatty acids and in the frequency of the $\mathrm{C}-\mathrm{O}$ stretching band of the phosphodiester and ribose $\left(1066 \mathrm{~cm}^{-1}\right)$ due to nucleic acids was observed $(P \leq 0.05$ and $P \leq 0.001$, respectively; Table 2 ). Moreover, the frequency of the $\mathrm{PO}_{2}$ asymmetric stretching band $\left(1236 \mathrm{~cm}^{-1}\right)$ was significantly shifted to lower levels in the VAD group ( $P \leq 0.01)$. In addition, in this group, the frequency of the N-type sugar $\left(876 \mathrm{~cm}^{-1}\right)$ band representing RNA and DNA significantly shifted to lower levels and the frequency of Z-type DNA $\left(925 \mathrm{~cm}^{-1}\right)$ bands significantly shifted to higher levels ( $P \leq 0 \cdot 001$ and $P \leq 0 \cdot 01$, respectively). However, both vitamin A supplementation and VAD, compared with PC, led to a significant shift in the frequencies of the RNA bands centred at $990 / \mathrm{cm}(P \leq 0 \cdot 001)$. Moreover, significant decreases in the areas of these bands were observed in the VAD group when compared with the CON group $(P \leq 0 \cdot 05)$.

\section{Discussion}

In the present study, the effect of VAD on the content, structure and function of molecules in the hippocampus, the brain structure crucial for learning and memory formation ${ }^{(35)}$, was investigated. Although the effects of VAD in the hippocampus have been studied extensively as well as the effects of VAD in other regions of the brain such as the striatum, cerebellum, hindbrain and cortex have been investigated in some studies ${ }^{(12,36-40)}$, none of these studies has investigated molecular changes in these brain structures. Therefore, the present study is the first to investigate the effect of VAD on hippocampal macromolecules.

VAD is caused due to inadequate intake of vitamin A. This condition can be caused by either total depletion or reduction of vitamin $\mathrm{A}$ in the diet. Both these mechanisms can lead to a similar effect at the organismal level. For example, Antipatis et al. ${ }^{(41)}$ have previously found that pregnant rats fed a vitamin A-deficient diet and a vitamin A-low diet have plasma retinol concentrations 50 and $30 \%$ lower than those of pregnant rats fed a vitamin A-sufficient diet. Lower plasma retinol concentrations result in many disorders such as liver disease ${ }^{(42)}$ and lung disease ${ }^{(43)}$. For example, chronic hepatitis $\mathrm{C}$ patients exhibit a reduction of $30-35 \%$ in plasma retinol concentrations when compared with normal patients ${ }^{(42)}$. In another study, rats fed a diet with reduced vitamin A content accidentally have been found to exhibit an increase in mortality from urinary tract infection in contrast to that observed in studies in rats fed vitamin A-free diets ${ }^{(44)}$. Furthermore, both vitamin A-depleted animals and animals fed a vitamin A-low diet have been found to exhibit significantly reduced weight gain $^{(44)}$. Therefore, feeding animals with a vitamin A-depleted diet either totally or partially may cause significant health problems.

In the present study, the spectral analysis of hippocampal tissue using HCA and PCA clearly showed that both the CON and PC groups differed significantly from the VAD group with respect to spectral data, while no significant differences were observed in the spectral data of the control groups.

As has been mentioned earlier, brain tissue is highly sensitive to free radicals because of its high rate of oxidative metabolic activity and high concentrations of oxidative substances (PUFA and metals such as Fe) and low concentrations of antioxidants $^{(45)}$. When molecules possessing antioxidant activity such as vitamin A are removed from biological systems, 
brain becomes highly prone to lipid peroxidation. In the present study, as has been suggested previously, information about lipid peroxidation was obtained by analysing the integrated area of the olefinic band $\left(3014 \mathrm{~cm}^{-1}\right)$ arising from the $\mathrm{CH}$ stretching mode of $\mathrm{HC}-\mathrm{CH}$ groups as these groups are highly sensitive to oxidative attack and highly prone to lipid peroxidation because of their double bond content ${ }^{(16,46-48)}$. Furthermore, a significant decrease in the area of the olefinic band and thus a decrease in the number of double bonds in fatty acids and a decrease in the olefinic $-\mathrm{CH}$ :lipid ratio were observed in the VAD group. These findings indicate a loss of olefinic bonds ${ }^{(46)}$ and thus a decrease in the content of unsaturated lipids resulting from the increased lipid peroxidation $^{(31-33,45)}$. Moreover, Fonzo et al. ${ }^{(49)}$ demonstrated increased lipid peroxidation in the hippocampus of vitamin A-deficient rats, which also confirms our findings.

Lipid peroxidation leads to the oxidative degradation of lipids due to the fragmentation of long chains resulting in a decrease in lipid content. In the present study, a significant decrease in the areas of lipid bands $\left(\mathrm{CH}_{2}\right.$ asymmetric and symmetric stretching, $\mathrm{CH}_{3}$ asymmetric stretching and $\mathrm{CH}_{2}$ bending), indicating an overall decrease in lipid content, was observed in the VAD group. In line with the results of the present study, Khanna \& Reddy ${ }^{(50)}$ reported a decrease in hepatic phospholipid content in rats maintained on a vitamin Adeficient diet. To better reveal the spectroscopic changes in lipid content, and thus variations in lipid synthesis, the band ratios of some specific lipids to total lipids were evaluated ${ }^{(16,51)}$. The phospholipids of cell membranes in all living organisms are strongly affected by either excessive loss or insufficient dietary supply of macro- and micronutrients, leading to pathophysiological conditions ${ }^{(52)}$. In the present study, a significant decrease in the carbonyl:lipid ratio (decrease in carbonyl content) and the $\mathrm{CH}_{3}$ asymmetric stretching:lipid ratio (decrease in methyl concentration) and an increase in the $\mathrm{CH}_{2}$ asymmetric stretching:lipid ratio (increase in the acyl chain length ${ }^{(51)}$ ), indicating a relative increase in the saturation levels of lipids in the hippocampus of vitamin Adeficient rats occurring parallel to the decrease in the area of the olefinic band, were observed. These findings point to the protective antioxidant effects of vitamin A in biological systems. Changes in lipid content and composition strongly affect the structure and functions of the cell membrane. It has been demonstrated that the degree of fatty acid unsaturation in the cell membrane determines its biophysical properties, which in turn influence many critical membraneassociated functions including the activity of membranebound enzymes ${ }^{(53)}$.

Information about the contents of cholesteryl esters and TAG is generally acquired from the areas of spectral bands located in the 1740 and $1170 / \mathrm{cm}$ regions, which are due to the $\mathrm{C}-\mathrm{O}$ stretching functional groups. The $\mathrm{C}-\mathrm{O}$ ester band gives valuable information about the interfacial region of lipid assemblies in addition to information about lipid accumulation $^{(54)}$. The frequency of the $\mathrm{C}-\mathrm{O}$ ester carbonyl band near the aqueous part of membrane lipids, in the interfacial region, is an important marker for lipid-lipid and lipid-protein interactions via hydrogen bonds because of their proton-accepting ability ${ }^{(28,55)}$. In the present study, the frequency of this band significantly shifted to lower levels in the VAD group, suggesting an increase in the hydrogenbonding ability of lipids ${ }^{(56)}$. This indicates the re-orientation of the lipid head groups with a decrease in free carbonyl groups $^{(57)}$.

As lipids constitute the main component of the cell membrane, their order parameters and fluidity are definitely important for the functioning of the membrane. The order information can be obtained from the frequencies of the $\mathrm{CH}_{2}$ asymmetric and symmetric stretching bands ${ }^{(28,58)}$. The frequencies of these bands are conformation sensitive and respond to changes in the trans:gauche ratio in acyl chains. A lower frequency indicates lower acyl chain flexibility, which implies lipid ordering ${ }^{(58)}$. In the present study, the frequencies of these bands significantly shifted to lower levels in the VAD group, indicating that VAD leads to an increase in lipid order and thus a decrease in acyl chain flexibility. The significant shift to higher levels observed in the frequency of the $\mathrm{CH}_{2}$ symmetric stretching band in the CON group when compared with the PC group additionally supports the lipiddisordering capacity and -recovery effect of vitamin A.

Lipid fluidity or dynamics is detected by monitoring the bandwidths of the $\mathrm{CH}_{2}$ stretching bands ${ }^{(59)}$. An increase in the bandwidth corresponds to an increase in lipid content and thus membrane fluidity. In the present study, the bandwidths of the $\mathrm{CH}_{2}$ asymmetric and symmetric stretching bands decreased significantly in the VAD group, indicating a decrease in lipid dynamics and membrane fluidity. The decrease in lipid dynamics due to VAD has also been reported previously ${ }^{(60)}$. The decrease in membrane fluidity may be associated with lipid peroxidation ${ }^{(16)}$. The loss of membrane motion (decrease in membrane fluidity) due to oxidative stress and the restoration of membrane fluidity after the administration of melatonin (a potent antioxidant) in biological and liposomal membranes have been reported previously ${ }^{(61)}$. These findings again point to the protective antioxidant effects of vitamin $\mathrm{A}$ in the brain and the importance of vitamin A for maintaining the integrity of cell membranes.

Vitamin A-induced alterations in membrane fluidity may also be associated with alterations in the contents of saturated and unsaturated lipids, proteins and cholesterol as well as with the change in the lipid:protein ratio ${ }^{(26,52)}$, as has been observed in the present study. Changes in phospholipid metabolism in different tissues of vitamin A-deficient rats have also been reported previously ${ }^{(52)}$.

As has been mentioned earlier, FT-IR spectroscopy provides a greater opportunity to simultaneously examine proteins and lipids in biological tissues ${ }^{(16,62)}$. In the present study, a significant increase was observed in the amide I:amide II ratio in the VAD group, which is in accordance with the results of previous studies indicating an alteration in the composition of cellular proteins ${ }^{(16,63)}$. It is known that this ratio changes due to diseased states, as has been reported previously ${ }^{(20,64)}$ In addition to this, in the present study, shifts were observed in the frequencies of the amide I and II bands in the VAD group, indicating conformational alterations in the structure of proteins due to VAD. The variations in the frequencies of 
the amide $\mathrm{A}, \mathrm{CH}_{3}$ symmetric stretching and amide III bands, mainly originating from the functional groups of proteins, also support the conformational changes in proteins occurring under dietary VAD. To further investigate alterations in the secondary structure of proteins, the amide I band region, corresponding to absorption values between 1600 and 1700/cm, was analysed using the ANN and intensity measurement methods. Recently, this approach has been successfully applied to tissue and membrane proteins by our group ${ }^{(7,16,26)}$. In the present study, a significant decrease in the $\alpha$-helix structure content and a significant increase in the turn and random coil structure contents were observed, revealing an alteration in the secondary structure of proteins due to VAD. The increase in the random coil structure content indicates protein denaturation, which may be due to oxidative stress and free radical formation ${ }^{(65)}$. As can be seen from Table 4 , no significant changes were observed in the turn and random coil structure contents in the control groups, supporting the protective effect of vitamin A on the secondary structure of proteins. Based on the protein denaturation findings in the VAD group, it can be proposed that VAD induces protein structural/conformational changes and thus alterations in protein function. There are only a few studies that have been carried out on the role of vitamins or micronutrients in the protein structure in the literature. In one of these studies, it has been demonstrated that vitamin $\mathrm{E}$ prevents the oxidative stress-induced denaturation of nerve proteins ${ }^{(66)}$. Moreover, Toyran et $a l .^{(18,67)}$ investigated the effect of Se supplementation on the secondary structure of proteins in rat heart, heart apex and right ventricle and reported significant structural alterations in these proteins. In addition to structural studies, there are a few studies that have investigated vitamin deficiency-induced proteome alterations. For example, Zhang et $a l .{ }^{(38)}$ demonstrated vitamin A depletion-induced protein alterations in cortical and hippocampal tissues. Moreover, an association between cobalamin (vitamin $\mathrm{B}_{12}$ ) deficiency and alterations in the cerebrospinal fluid proteome has been demonstrated $^{(68)}$. The role of vitamin D deficiency in protein expression alterations in the brain has been demonstrated by Almeras et al. ${ }^{(69)}$. However, these studies are based on only protein expression analysis, i.e. quantitative, but not on structural analysis. Therefore, further studies are required to elucidate the association between vitamin deficiencies and protein structural/conformational changes.

It can be inferred that protein denaturation leads to alterations in hippocampal cell function, as cell structure is closely associated with function. Cocco et al. ${ }^{(13)}$ suggested that VAD leads to the impairment of cholinergic neurotransmission and a damaged structure of CA1 neurons in the hippocampus of rats. Moreover, the decrease in hippocampal neuron number under VAD has also been reported ${ }^{(70)}$. Therefore, the damaged neurons and/or decreased number of neurons and thus the impairment of neurotransmission prove the loss of cell activity.

These structural changes in proteins may also lead to alterations in hippocampus-dependent behaviour such as spatial memory impairments, as it has previously been reported that VAD impairs spatial learning and memory due to lower levels of histone acetylation of retinoic acid nuclear receptor- $\alpha^{(71)}$.

Any variation in the lipid:protein ratio gives information about the variation in the lipid and/or protein asymmetry, which is also closely associated with membrane function ${ }^{(25,26)}$. In the present study, with the decrease in the total lipid content and no change in the protein content, the lipid:protein ratio decreased significantly in the VAD group, suggesting an alteration in the lipid asymmetry in the cell membranes of vitamin A-deficient rats. It has been reported that the disruption of lipid asymmetry leads to a change in the intra- and intercellular ion concentrations and thus membrane functions ${ }^{(72)}$.

The $1300-1000 / \mathrm{cm}$ spectral range is commonly coupled with the IR bands of the stretching modes of the $\mathrm{P}-\mathrm{O}$ bond present in the $\mathrm{PO}_{2}^{-}$moieties of phospholipids and nucleic acids and with distinct ring vibrations of carbohydrates ( $\mathrm{C}-\mathrm{O}, \mathrm{C}-\mathrm{C}$ and $\mathrm{C}-\mathrm{O}-\mathrm{C}$ ) such as the sugars in the backbone of DNA and RNA ${ }^{(25,73)}$. The phosphate stretching vibrations are believed to provide valuable information about the head groups of the phospholipids in the polar-non-polar interface of membranous structures ${ }^{(26)}$. Furthermore, these IR bands can also help to monitor alterations in the quantity, conformational state, and degree and position of phosphorylation of molecules in DNA and $\mathrm{RNA}^{(54)}$. The spectral region between 995 and $990 / \mathrm{cm}$ is assigned to the ribose-phosphate main chain vibrations of $\mathrm{RNA}^{(27)}$. In the present study, a significant decrease was observed in RNA content in the VAD group, indicating a suppression of gene transcription. The vibration of N-type sugars in the sugar phosphate backbone of nucleic acids is centred at $876 / \mathrm{cm}^{(28)}$. In the present study, a significant increase in the area of the N-type sugar band and a significant decrease in the areas of other DNA bands (925 and $1065 \mathrm{~cm}^{-1}$ ) were observed in the VAD group, indicating that VAD causes substantial alterations in the content of hippocampal nucleic acids, as has been reported previously for other organ systems ${ }^{(74)}$. The shift in the frequencies of specific RNA and DNA bands located in the 995 and $925 / \mathrm{cm}$ regions can be attributed to conformational or structural changes in nucleic acids ${ }^{(75,76)}$. Some studies have reported an association between nucleic acid bands and gene expression. For example, one of these studies has demonstrated an association between gene expression and DNA conformation ${ }^{(77)}$. Moreover, McClintick et al. ${ }^{(78)}$ reported that VAD induces alterations in the hepatic expression of genes involved in fatty acid metabolism, peroxisomal function, glycolysis, and glutamate metabolism, which supports our findings. Recent studies have shown that deficiencies of individual nutrients can alter DNA methylation status and subsequently alter gene expression ${ }^{(79)}$. These findings are consistent with the decrease in the overall RNA content in the hippocampus of vitamin A-deficient rats observed in the present study, because of the oxidative stress-related inhibition of RNA synthesis as reported previously ${ }^{(80)}$.

As has been mentioned earlier, the frequency of the $\mathrm{PO}_{2}$ asymmetric stretching band is between 1220 and $1260 / \mathrm{cm}$ and indicates the degree of hydrogen bonding ${ }^{(55,81)}$. It has been shown that the frequency of the $\mathrm{PO}_{2}$ asymmetric stretching vibration band shifts to lower levels as hydrogen bonding 
increases $^{(32)}$. In the absorption spectra of hippocampal tissue, in the region of the $\mathrm{PO}_{2}$ asymmetric stretching band, two bands located in the 1262 and $1236 / \mathrm{cm}$ regions were observed. The band located in the $1262 / \mathrm{cm}$ region is due to non-hydrogen-bonded $\mathrm{PO}_{2}^{-}$groups and the band located in the $1236 / \mathrm{cm}$ region is due to fully hydrogen-bonded $\mathrm{PO}_{2}^{-}$ groups. In the spectra, a significant shift to lower levels in the frequency of the band located in the $1236 / \mathrm{cm}$ region can result from an increase in the hydrogen-bonding capacity of nucleic acids, which is the same as that observed for lipids. These data suggest that structural changes in DNA and RNA can also be associated with changes in hydrogen bonding in DNA and RNA backbones due to increasing nucleic acid hydration under $\mathrm{VAD}^{(82)}$

The results of the present study demonstrate that vitamin A, which at higher doses has been reported to act as a pro-oxidant adversely affecting living tissues ${ }^{(6)}$, at low-tomoderate doses exhibits beneficial effects, many of which arise from its antioxidant properties. Dietary exclusion of vitamin A for 3 months led to significant alterations in the composition and structure of hippocampal lipids with a dramatic decrease in lipid content, an increase in lipid order, and a significant decrease in membrane dynamics. Moreover, the composition and secondary structure of proteins and nucleic acids were altered. The molecular changes induced by VAD may attenuate gene expression and disturb optimal membrane fluidity and lipid-protein as well as proteinprotein interactions, which are important for normal membrane functions especially in the nervous system. Therefore, further investigations should be conducted to justify the structural and functional alterations in the molecular constituents of tissues due to VAD.

\section{Acknowledgements}

The present study was supported by a grant from the Turkish Scientific and Technical Council (TÜBITAK), SBAG-110S083, provided to E. J.-D. and by the METU Scientific Research Foundation; B. E.-C. was a recipient of the PhD scholarship from the TÜBITAK.

The authors' contributions are as follows: E. J.-D. and F. S. designed the study; B. E.-C. conducted the study; B. E.-C. and N. S.-O. analysed the data; M. S. conducted the PCA and ANN analysis; B. E.-C., N. S.-O., E. J.-D. and F. S. wrote the article; F. S. had primary responsibility for the final content. All authors read and approved the final version of the manuscript.

None of the authors has any conflicts of interest to declare.

\section{References}

1. Duester G (2008) Retinoic acid synthesis and signalling during early organogenesis. Cell 134, 921-931.

2. Sporn MB, Roberts AB \& Goodman DS (1994) The Retinoids: Biology, Chemistry and Medicine, 2nd ed. New York: Raven Press.

3. Boucheron-Houston C, Canterel-Thouennon L, Lee TL, et al. (2013) Long-term vitamin A deficiency induces alteration of adult mouse spermatogenesis and spermatogonial differentiation: direct effect on spermatogonial gene expression and indirect effects via somatic cells. I Nutr Biochem 24, 1123-1135.

4. Mactier H \& Weaver LT (2005) Vitamin A and preterm infants: what we know, what we don't know, and what we need to know. Arch Dis Child Fetal Neonatal Ed 90, 103-108.

5. Fenaux P, Chomienne C \& Degos L (2001) Treatment of acute promyelocytic leukaemia. Best Pract Res Clin Haematol 14, 153-174.

6. Zaidi SMKR \& Banu N (2004) Antioxidant potential of vitamins $\mathrm{A}, \mathrm{E}$ and $\mathrm{C}$ in modulating oxidative stress in rat brain. Clin Chim Acta 340, 229-233.

7. Elibol-Can B, Jakubowska-Doğru E, Severcan M, et al. (2011) The effects of short-term chronic ethanol intoxication and ethanol withdrawal on the molecular composition of the rat hippocampus by FT-IR spectroscopy. Alcohol Clin Exp Res 35, 2050-2062.

8. Halliwell B (2006) Oxidative stress and neurodegeneration: where are we now? J Neurochem 97, 1634-1658.

9. Wilson JX (1997) Antioxidant defense of the brain: a role for astrocytes. Can J Physiol Pharmacol 75, 1149-1163.

10. Kashif R, Zaidi SM \& Banu N (2004) Antioxidant potential of vitamins $\mathrm{A}, \mathrm{E}$ and $\mathrm{C}$ in modulating oxidative stress in rat brain. Clin Chim Acta 340, 229-233.

11. Bonnet E, Touyarot K, Alfos S, et al. (2008) Retinoic acid restores adult hippocampal neurogenesis and reverses spatial memory deficit in vitamin A deprived rats. PLoS ONE 3, e3487.

12. Misner DL, Jacobs S, Shimizu Y, et al. (2001) Vitamin A deprivation results in reversible loss of hippocampal longterm synaptic plasticity. Proc Natl Acad Sci USA $\mathbf{9 8}$, 11714-11719.

13. Cocco S, Diaz G, Stancampiano R, et al. (2002) Vitamin A deficiency produces spatial learning and memory impairment in rats. Neuroscience 115, 475-482.

14. Mingaud F, Mormede C, Etchamendy N, et al. (2008) Retinoid hyposignaling contributes to aging-related decline in hippocampal function in short-term/working memory organization and long-term declarative memory encoding in mice. J Neurosci 28, 279-291.

15. World Health Organization (2009) Global Prevalence of Vitamin A Deficiency in Populations at Risk 1995-2005, WHO Global Database on Vitamin A Deficiency. Geneva: WHO.

16. Cakmak G, Zorlu F, Severcan M, et al. (2011) Screening of restoring effect of amifostine on radiation induced structural and functional variations in rat liver microsomal membranes by FT-IR spectroscopy. Anal Chem 83, 2438-2444.

17. Garip S, Yapici E, Ozek NS, et al. (2010) Evaluation and discrimination of simvastatin-induced structural alterations in proteins of different rat tissues by FTIR spectroscopy and neural network analysis. Analyst 135, 3233-3241.

18. Toyran N, Severcan F, Severcan M, et al. (2008) Effects of selenium supplementation on rat heart apex and right ventricle myocardia by using FTIR spectroscopy: a cluster analysis and neural network approach. Food Chem 110, 590-597.

19. Akkas SB, Severcan M, Yilmaz O, et al. (2007) Effects of lipoic acid supplementation on rat brain tissue: an FTIR and neural network study. Food Chem 105, 1281-1288.

20. Bozkurt O, Haman Bayari S, Severcan M, et al. (2012) Structural alterations in rat liver proteins due to streptozotocininduced diabetes and the recovery effect of selenium: Fourier transform infrared microspectroscopy and neural network study. J Biomed Opt 17, 076023. 
21. Siebert F (1995) Infrared spectroscopy applied to biochemical and biological problems. Methods Enzymol $\mathbf{2 4 6}$ 501-526.

22. Barth A \& Haris P (2009) Biological and Biomedical Infrared Spectroscopy, vol. 2, p. 448. Amsterdam: IOS Press.

23. Severcan F \& Haris P (2012) Vibrational Spectroscopy in Diagnosis and Screening, vol. 6, p. 432. Amsterdam: IOS Press.

24. Celik T, Cakir E, Kayir H, et al. (2005) The effects of chronic ethanol consumption and withdrawal on passive avoidance task and serum cholinesterase level in rats. Prog Neuropsychopharmacol Biol Psychiatry 29, 505-509.

25. Ozek NS, Sara Y, Onur R, et al. (2010) Low dose simvastatin induces compositional, structural and dynamical changes on rat skeletal extensor digitorum longus muscle tissue. Biosci Rep 30, 41-50.

26. Bozkurt O, Severcan M \& Severcan F (2010) Diabetes induces compositional, structural and functional alterations on rat skeletal soleus muscle revealed by FTIR spectroscopy: a comparative study with EDL muscle. Analyst 135, 3110-3119.

27. Banyay M, Sarkar M \& Graslund A (2003) A library of IR bands of nucleic acids in solution. Biophys Chem 104, 477-488.

28. Severcan F, Sahin I \& Kazanc1 N (2005) Melatonin strongly interacts with zwitterionic model membranes evidence from Fourier transform infrared spectroscopy and differential scanning calorimetry. Biochim Biophys Acta 1668, 215-222.

29. Severcan M, Haris PI \& Severcan F (2001) Estimation of protein secondary structure from FTIR spectra using neural networks. J Mol Struct 565, 383-387.

30. Severcan M, Haris PI \& Severcan F (2004) Using artificially generated spectral data to improve protein secondary structure prediction from Fourier transform infrared spectra of proteins. Anal Biochem 332, 238-244.

31. Cakmak G, Togan I \& Severcan F (2006) 17-Estradiol induced compositional, structural and functional changes in rainbow trout liver, revealed by FT-IR spectroscopy: a comparative study with nonylphenol. Aquat Toxicol 77 , 53-63.

32. Severcan F, Kaptan N \& Turan B (2003) Fourier transform infrared spectroscopic studies of diabetic rat heart crude membranes. Spectroscopy 17, 569-577.

33. Melin A, Perromat A \& Deleris G (2000) Pharmacologic application of Fourier transform IR spectroscopy: in vivo toxicity of carbon tetrachloride on rat liver. Biopolymers 57, 160-168.

34. Severcan F, Toyran N, Kaptan N, et al. (2000) Fourier transform infrared study of diabetes on rat liver and heart tissues in the $\mathrm{C}-\mathrm{H}$ region. Talanta $\mathbf{5 3}, 55-59$.

35. Jarrard LE (1993) On the role of the hippocampus in learning and memory in the rat. Behav Neural Biol 60, 9-26.

36. McCaffery PJ, Adams J, Maden M, et al. (2003) Too much of a good thing: retinoic acid as an endogenous regulator of neural differentiation and exogenous teratogen. Eur $J$ Neurosci 18, 457-472.

37. Zhang M, Ji B, Zou H, et al. (2010) Vitamin A depletion alters sensitivity of motor behavior to MK-801 in C57BL/6J mice. Behav Brain Funct 6, 7.

38. Zhang M, Huang K, Zhang Z, et al. (2011) Proteome alterations of cortex and hippocampus tissues in mice subjected to vitamin A depletion. J Nutr Biochem 22, 1003-1008.

39. Etchamendy N, Enderlin V, Marighetto A, et al. (2003) Vitamin A deficiency and relational memory deficit in adult mice: relationships with changes in brain retinoid signaling. Behav Brain Res 145, 37-49.
40. Zetterstrom RH, Lindqvist E, Mata de Urquiza A, et al. (1999) Role of retinoids in the CNS: differential expression of retinoid binding proteins and receptors and evidence for presence of retinoic acid. Eur J Neurosci 11, 407-416.

41. Antipatis C, Grant G \& Ashworth CJ (2000) Moderate maternal vitamin A deficiency affects perinatal organ growth and development in rats. Br J Nutr 84, 125-132.

42. Newsome PN, Beldon I, Moussa Y, et al. (2000) Low serum retinol levels are associated with hepatocellular carcinoma in patients with chronic liver disease. Aliment Pharmacol Ther 14, 1295-1301.

43. Spears K, Cheney C \& Zerzan J (2004) Low plasma retinol concentrations increase the risk of developing bronchopulmonary dysplasia and long-term respiratory disability in very-low-birth-weight infants. Am J Clin Nutr 80, 1589-1594.

44. Munday JS, McKinnon H, Aberdein D, et al. (2009) Cystitis, pyelonephritis, and urolithiasis in rats accidentally fed a diet deficient in vitamin A. J Am Assoc Lab Anim Sci 48, $790-794$.

45. Zwart LL, Meerman JHN, Commandeur JNM, et al. (1999) Biomarkers of free radical damage applications in experimental animals and in humans. Free Radic Biol Med 26, 202-226.

46. Sills RH, Moore DJ \& Mendelsohn R (1994) Erythrocyte peroxidation: quantitation by Fourier transform infrared spectroscopy. Anal Biochem 218, 118-123.

47. Mamarelis I, Pissaridi K, Dritsa V, et al. (2010) Oxidative stress and atherogenesis. An FT-IR spectroscopic study. In Vivo 24, 883-888.

48. Reiter RJ (1995) Oxidative processes and antioxidative defense mechanisms in the aging brain. FASEB J 9, 526-533.

49. Fonzo LS, Golini RS, Delgado SM, et al. (2009) Temporal patterns of lipoperoxidation and antioxidant enzymes are modified in the hippocampus of vitamin A-deficient rats. Hippocampus 19, 869-880.

50. Khanna A \& Reddy TS (1983) Effect of undernutrition and vitamin A deficiency on the phospholipid composition of rat tissues at 21 days of age - I. Liver, spleen and kidney. Int J Vitam Nutr Res 53, 3-8.

51. Cakmak G, Miller LM, Zorlu F, et al. (2012) Amifostine, a radioprotectant agent, protects rat brain tissue lipids against ionizing radiation induced damage: an FTIR microspectroscopic imaging study. Arch Biochem Biophys 520, 67-73.

52. Gimenez MS, Oliveros LB \& Gomez NN (2011) Nutritional deficiencies and phospholipid metabolism. Int J Mol Sci 12, 2408-2433.

53. Horrocks LA \& Farooqui AA (2004) Docosahexaenoic acid in the diet: its importance in maintenance and restoration of neural membrane function. Prostaglandins Leukot Essent Fatty Acids 70, 361-372.

54. Kneipp J, Lasch P, Baldauf E, et al. (2000) Detection of pathological molecular alterations in scrapie-infected hamster brain by Fourier transform infrared (FT-IR) spectroscopy. Biochim Biophys Acta 1501, 189-199.

55. Wong PTT, Wong RK, Caputo TA, et al. (1991) Infrared spectroscopy of exfoliated human cervical cells: evidence of extensive structural changes during carcinogenesis. Proc Natl Acad Sci U S A 88, 10988-10992.

56. Gorgulu ST, Dogan M \& Severcan F (2007) The characterization and differentiation of higher plants by Fourier transform infrared spectroscopy. Appl Spectrosc 61, 300-308.

57. López-García F, Micol V, Villalaín J, et al. (1993) Infrared spectroscopic study of the interaction of diacylglycerol with phosphatidylserine in the presence of calcium. Biochim Biophys Acta 1169, 264-272. 
58. Severcan F (1997) Vitamin E decreases the order of the phospholipid model membranes in the gel phase: an FTIR study. Biosci Rep 17, 231-235.

59. Severcan F, Kazanci N \& Zorlu F (2000) Tamoxifen increases membrane fluidity at high concentrations. Biosci Rep 20, $177-184$.

60. Hamm MW, Chan V \& Wolf G (1987) Liver microsomal membrane fluidity and lipid characteristics in vitamin A-deficient rats. Biochem J 245, 907-910.

61. Garcia JJ, Reiter RJ, Guerrero JM, et al. (1997) Melatonin prevents changes in microsomal membrane fluidity during induced lipid peroxidation. FEBS Lett 408, 297-300.

62. Szalontai B, Nishiyama Y, Gombos Z, et al. (2000) Membrane dynamics as seen by Fourier transform infrared spectroscopy in a cyanobacterium, Synechocystis PCC 6803. The effects of lipid unsaturation and the protein-to-lipid ratio. Biochim Biophys Acta 1509, 409-419.

63. Yu P, Doiron K \& Liu D (2008) Shining light on the differences in molecular structural chemical makeup and the cause of distinct degradation behavior between maltingand feed-type barley using synchrotron FTIR microspectroscopy: a novel approach. J Agric Food Chem 56, 3417-3426.

64. Szczerbowska-Boruchowska M, Dumas P, Kastyak MZ, et al. (2007) Biomolecular investigation of human substantia nigra in Parkinson's disease by synchrotron radiation Fourier transform infrared microspectroscopy. Arch Biochem Biophys 459, 241-248.

65. Davies KA (1987) Protein damage and degradation by oxygen radicals. I. General aspects. J Biol Chem 262, 9895-9901.

66. Kaneai N, Arai M, Takatsu H, et al. (2012) Vitamin E inhibits oxidative stress-induced denaturation of nerve terminal proteins involved in neurotransmission. J Alzheimers Dis $\mathbf{2 8}$, 183-189.

67. Toyran N, Turan B \& Severcan F (2007) Selenium alters the lipid content and protein profile of rat heart: an FTIR microspectroscopic study. Arch Biochem Biophys 458, 184-193.

68. Gianazza E, Veber D, Eberini I, et al. (2003) Cobalamin (vitamin $\mathrm{B}_{12}$ )-deficiency-induced changes in the proteome of rat cerebrospinal fluid. Biochem J 374, 239-246.

69. Almeras L, Eyles D, Benech P, et al. (2007) Developmental vitamin $\mathrm{D}$ deficiency alters brain protein expression in the adult rat: implications for neuropsychiatric disorders. Proteomics 7, 769-780.
70. Guo M, Bryant J, Sultana S, et al. (2012) Effects of vitamin A deficiency and opioids on hippocampal neuronal numbers and parvalbumin expression in the HIVA-1 transgenic rat. Curr HIV Res 10, 463-468.

71. Hou N, Ren L \& Gong M, et al. (2014) Vitamin A deficiency impairs spatial learning and memory: the mechanism of abnormal CBP-dependent histone acetylation regulated by retinoic acid receptor $\alpha$. Mol Neurobiol (Epublication ahead of print version 24 May 2014).

72. Becker WM, Kleinsmith LJ \& Hardin J (2003) Membranes: their structure, function, and chemistry. In The World of the Cell, 5th ed., pp. 158-195 [B Wilbur, editor]. San Francisco, CA: Pearson Education, Inc.

73. Mendelsohn R \& Mantsch HH (1986) Fourier transform infrared studies of lipid-protein interactions. In Progress in Lipid Protein Interactions, vol. 2, pp. 103-146 [A Watts and JJHHM De Pont, editors]. New York: Elsevier.

74. Feng Y, Zhao LZ, Hong L, et al. (2013) Alteration in methylation pattern of GATA-4 promoter region in vitamin Adeficient offspring's heart. J Nutr Biochem 24, 1373-1380.

75. Turker S, Ilbay G, Severcan M, et al. (2014) Investigation of compositional, structural, and dynamical changes of pentylenetetrazol-induced seizures on a rat brain by FT-IR spectroscopy. Anal Chem 86, 1395-1403.

76. Whelan DR, Bambery KR, Heraud P, et al. (2011) Monitoring the reversible B to A-like transition of DNA in eukaryotic cells using Fourier transform infrared spectroscopy. Nucleic Acids Res 39, 5439-5448.

77. Kohwi Y \& Kohwi-Shigematsu T (1991) Altered gene expression correlates with DNA structure. Genes Dev 5, $2547-2554$.

78. McClintick JN, Crabb DW, Tian H, et al. (2006) Global effects of vitamin A deficiency on gene expression in rat liver: evidence for hypoandrogenism. J Nutr Biochem 17, 345-355.

79. Choi SW \& Friso S (2010) Epigenetics: a new bridge between nutrition and health. Adv Nutr 1, 8-16.

80. Ding Q, Dimayuga E \& Keller JN (2007) Oxidative stress alters neuronal RNA- and protein-synthesis: implications for neural viability. Free Radic Res 41, 903-910.

81. Rigas B, Morgellot S, Goldman IS, et al. (1990) Human colorectal cancers display abnormal Fourier-transform infrared spectra. Proc Natl Acad Sci U S A 87, 8140-8144.

82. Dovbeshko GI, Gridina NY, Kruglova EB, et al. (2000) FT-IR spectroscopy studies of nucleic acid damage. Talanta $\mathbf{5 3}$, 233-246. 